\title{
Changes in red blood cell membrane properties: the role of metabolic syndrome components
}

\author{
${ }^{1}$ Yu.G. Birulina, ${ }^{1}$ I.V. Petrova, ${ }^{1}$ V.V. Ivanov, ${ }^{1,2}$ E.E. Buyko, ${ }^{1}$ R.R. Shaibekova, ${ }^{1}$ A.V. Grigoreva, \\ ${ }^{1}$ I.V. Kovalev, ${ }^{1}$ A.V. Nosarev, ${ }^{1}$ S.V. Gusakova \\ ${ }^{1}$ Siberian State Medical University, 2, Moscovsky Trakt, Tomsk, 634050; \\ ${ }^{2}$ Tomsk Polytechnic University, 30, Lenina Ave., Tomsk, 634050 \\ Russia
}

Received: December 1, 2020. Revised: May 26, 2021. Accepted: June 21, 2021. Published: June 23, 2021.

\begin{abstract}
Metabolic syndrome (MetS) is a cluster of metabolic, hormonal and hemodynamic disorders that contribute to a change in the structural and functional status of erythrocytes and contribute to dysregulation of their cation transport function, where $\mathrm{Ca}^{2+}$-dependent potassium channels ( $\mathrm{K}_{\mathrm{Ca}}$ channels) play an important role. A MetS model was performed using male Wistar rats, which were divided into control and experimental groups. Rats in the control group were fed standard rat chow. Rats in the experimental group were exposed to a high-fat and high-carbohydrate (HFHC) diet for 12 weeks. The data obtained indicate that the HFHC diet led to obesity, high blood pressure, hyperglycemia, impaired glucose tolerance, and dyslipidemia. The level of glutathione (GSH) decreased in the erythrocytes of rats suffering from MetS, but the level of malondialdehyde (MDA) increased. It was shown that the amplitude of the membrane potential of erythrocytes of rats with MetS changed depending on the acting agent: when stimulated with calcium ionophore A23187 it decreased, when the redox system ascorbat phenazine methosulfate was used, it increased compared to the control group. The data obtained indicate that a HFHC diet leads to changes in the physical and chemical properties of the erythrocyte membrane.
\end{abstract}

Keywords - erythrocytes, metabolic syndrome, oxidative stress, $K_{\text {Ca }}$ channels.

\section{INTRODUCTION}

$\mathrm{D}$ ISODERS of the circulatory system that may develop as a result of metabolic syndrome (MetS) are one of the problems studied by biological and medical science [1] - [3]. The prevalence of MetS in modern society has been rapidly increasing in recent years, which is becoming the cause of increased morbidity and mortality of the population [1], [4].
MetS is defined as a condition characterized by visceral obesity and at least two of the following parameters: high triglyceride levels (TAG), low level of high-density lipoproteins (HDL), high blood pressure (BP) and hyperglycemia [2]. Thus, MetS is a complex of metabolic, hormonal and hemodynamic disorders that increases the risk of type 2 diabetes, non-alcoholic fatty liver disease and cardiovascular diseases [7].

Changes in the properties of the plasma membrane and the function of erythrocytes were found in MetS and type 2 diabetes [6], [7]. It should be noted that erythrocytes traditionally serve as a model for studying ion transport of plasma membranes in health and disease, as well as for assessing the degree of membrane damage in case of a pathological process in the body.

Structural and functional disorders of erythrocytes make a contribution to the MetS development. Disorganization and modulation of the erythrocyte membrane physical and chemical properties in case of metabolic disorders lead to dysregulation of its cation transport function, where an important role belongs to $\mathrm{Ca}^{2+}$-dependent potassium channels ( $\mathrm{K}_{\mathrm{Ca}}$ channels), whose activity determines red blood cells erypthosis [8], [9], as well as their deformability [10].

It is important to note that the regulation of ion transport systems is associated with the modification of sulfhydryl groups (SH-groups), which are extensively concentrated in the membrane and proteins of the cytoskeleton of erythrocytes, involved in maintaining the shape of cells. The erythrocyte membrane contains some components of the electron transport chain, usually present on the inner mitochondrial membrane [11], which can be involved in the regulation of erythrocyte $\mathrm{K}_{\mathrm{Ca}}$ channels.

The need to clarify the fundamental basis of hemorheological disorders and their role in the progression of cardiovascular pathology accompanying MetS requires an adequate experimental model of MetS. One of the most 
widespread methods of modeling MetS in animals is a special diet [12], [13]. In this respect, a high-fat and highcarbohydrate (HFHC) diet proved to be the most effective and reproducing the typical characteristics of MetS in animals [14], [15].

Thus, the aim of this work is to study the relationship between the components of MetS induced by a HFHC diet and the parameters of rat erythrocyte membrane.

\section{MATERIALS AND METHODS}

\section{A. Animals}

Male Wistar rats (220-250 g, $\mathrm{n}=23$ ) were fed ad libitum and housed in a 12-h light/dark cycle. Animals were treated in accordance with the Guide for the Care and Use of Laboratory Animals published by the US National Institutes of Health (NIH Publication No. 85-23, revised 1996). The Siberian State Medical University ethical approval number for the studies was 8201. Two groups were formed: 1) rats on a standard chow diet $(\mathrm{n}=11)$ - control group; 2$)$ rats on a high-fat, highcarbohydrates diet (HFHC diet, $\mathrm{n}=12$ ) - experimental group. The control group was fed food for laboratory animals Delta Feeds (Biopro, Russia), with fats accounting for $18 \%$ of the total calorie intake (total calories $3000 \mathrm{kcal} / \mathrm{kg}$ ). For the experimental group, we developed a diet that included the Delta Feeds feed described above (66\%), animal fat $(17 \%)$, fructose $(17 \%)$, dry milk $(0.3 \%)$ and cholesterol $(0.25 \%)$ with $20 \%$ fructose in drinking water (total calories $4400 \mathrm{kcal} / \mathrm{kg}$ ). The diet complied with the following criteria: fats accounted for $54 \%$ of the calories. The experiment lasted 12 weeks. At the end of the study body weight and BP (Systola, Neurobotics, Russia) were measured. A glucose tolerance test was performed in the 12 th week of the experiment. On the day of the experiment rats were euthanized by $\mathrm{CO}_{2}$ inhalation.

\section{B. Glucose Tolerance Test}

Plasma glucose concentrations were measured using a glucose-oxidase enzymatic commercial kit (Glucose, Chronolab Systems, Spain) and determined at $510 \mathrm{~nm}$ with a spectrophotometer (SP-2000, Russia). A load of $2.0 \mathrm{~g} / \mathrm{kg} 20 \%$ glucose solution (D-glucose, Sigma-Aldrich, USA) was administered by oral gavage. Blood glucose levels were measured, and tail blood was collected at 15, 30, 60, 90 and $120 \mathrm{~min}$ post glucose gavage.

\section{Biochemical tests}

Blood from the heart was collected in vacuum tubes with anticoagulants: $\mathrm{K}_{2}$ EDTA or lithium heparin. Blood plasma was obtained by centrifugation of EDTA whole blood $\left(4{ }^{\circ} \mathrm{C}\right.$, $8000 \mathrm{~g}, 6 \mathrm{~min}$ ) and plasma samples were stored in a freezer at $-70^{\circ} \mathrm{C}$.

The lipid spectrum of the blood plasma of animals (total cholesterol, LDL, HDL) was determined using an automatic biochemical analyzer (Architect c4000, Abbot, USA). Plasma triglyceride levels were measured by using enzymatic colorimetric assay kit (Triglycerides, Chronolab Systems,
Spain) and determined at $505 \mathrm{~nm}$ with a spectrophotometer (SP-2000, Russia).

Plasma insulin levels were measured by using Rat Ins1 / Insulin ELISA Kit (Sigma-Aldrich, USA) according to the manufacturer's instructions. The samples were measured using the Infinite 200 PRO microplate reader (Tecan $\mathrm{GmbH}$, Salzburg, Austria).

\section{Oxidative Stress Biomarkers}

Glutathione (GSH) levels in red blood cells suspension were measured by using an enzymatic recycling method [16]. GSH was measured by the 5,5'-di-thiobis-(2-nitrobenzoic acid) method on the day of blood collection from the erythrocyte lysate (from the washed cells) after protein precipitation by metaphosphoric acids. The results were expressed as $\mu \mathrm{mol}$ $\mathrm{GSH} / \mathrm{g} \mathrm{Hb}$.

Concentration of malondialdehyde (MDA) in red blood cells suspension was determined by the thiobarbituric acid assay and spectrophotometrically measured at $532 \mathrm{~nm}$ (SP2000, Russia) as previously reported by Jain S.K. et al. [17]. The results were expressed as nmol MDA/g Hb.

\section{E. Measurement of the activity of the $K_{C a}$ channels}

Assessment of $\mathrm{K}_{\mathrm{Ca}}$ channel activity was performed by recording membrane potential by changing the $\mathrm{pH}$ of a suspension of erythrocytes $(\mathrm{Ht}=3.8 \%)$ in the presence of a protonophore (CCCP, $20 \mu \mathrm{M})$ [18], [19]. Erythrocyte sediment was obtained from whole heparinized blood by centrifugation (4 ${ }^{\circ} \mathrm{C}, 1000 \mathrm{~g}, 5 \mathrm{~min}$ ), plasma and leukocytes were then removed, and the erythrocytes were washed twice with 150 $\mathrm{mM} \mathrm{NaCl}$ containing phosphate buffered saline $(5 \mathrm{mM}, \mathrm{pH}$ 7.4 ), under the same centrifugation conditions. The incubation medium contained $150 \mathrm{mM} \mathrm{NaCl}, 1 \mathrm{mM} \mathrm{KCl}, 1 \mathrm{mM} \mathrm{MgCl}_{2}$, $10 \mathrm{mM}$ glucose, and $10 \mu \mathrm{M} \mathrm{CaCl}_{2}\left(37^{\circ} \mathrm{C}\right)$. At the end of the experiment, Triton $\mathrm{X}-100$ was added to the erythrocyte suspension to a final concentration of $0.2 \%$. The amplitude of the hyperpolarization $(\mathrm{mV})$ of erythrocyte membrane caused by the activation of the $\mathrm{K}_{\mathrm{Ca}}$ channels by using $\mathrm{Ca}^{2+}$ ionophore A23187 $(0.5 \mu \mathrm{M})$ and ascorbate $(10 \mathrm{mM})$ - phenazine methosulfate (PMS, $0.1 \mathrm{mM}$ ) was registered. All reagents were purchased from Sigma-Aldrich (USA).

\section{F. Statistics}

Data are presented as the mean values \pm SD. Variables were assessed for normality by the Shapiro-Wilk test. To compare values between the groups, data were analyzed by the unpaired Student's t-test. Univariate relationships were estimated using Spearman's rank correlation. All statistical tests were carried out to a significance level of 0.05 . The data were analyzed using IBM SPSS Statistics 23 software.

\section{RESULTS}

Rats fed the HFHC diet for 12 weeks experienced an increase in systolic and diastolic BP and adipose tissue/body weight ratio (Table 1). It was shown that the mass of abdominal fat increased by 2,5 times in experimental rats. The 
data obtained indicate that rats in the experimental group have obesity. However, feeding animals a special diet does not always lead to the significant increase in body weight. In our experiment the final body weight did not differ between control and HFHC groups (Table 1). A possible explanation of this finding is the fact that animals of the HFHC group consumed less of the food enriched in fat and fructose, probably due to the higher caloric intake with this diet.

TABLE I PHYSIOLOGICAL PARAMETERS OF RATS

\begin{tabular}{|l|c|c|}
\hline \multirow{2}{*}{\multicolumn{1}{|c|}{ Parameter }} & \multicolumn{2}{|c|}{ Group } \\
\cline { 2 - 3 } & $\begin{array}{c}\text { Control } \\
(\mathrm{n}=11)\end{array}$ & $\begin{array}{c}\text { HFHC } \\
(\mathrm{n}=12)\end{array}$ \\
\hline Body weight, g & $376.6 \pm 28.9$ & $388.2 \pm 30.7$ \\
\hline Systolic BP, mm Hg & $123.2 \pm 8.8$ & $139.2 \pm 9.1^{*}$ \\
\hline Diastolic BP, mm Hg & $86.5 \pm 9.3$ & $101.4 \pm 12.2^{*}$ \\
\hline $\begin{array}{l}\text { Adipose tissue/body } \\
\text { weight ratio, g }\end{array}$ & $1.1 \pm 0.3$ & $2.8 \pm 0.4^{*}$ \\
\hline $\begin{array}{l}\text { Food intake, } \\
\text { g/day/group }\end{array}$ & $130.2 \pm 8.4$ & $101.7 \pm 9.8^{*}$ \\
\hline $\begin{array}{l}\text { Fluid intake, } \\
\text { ml/day/group }\end{array}$ & $249.5 \pm 11.9$ & $347.5 \pm 12.6^{*}$ \\
\hline
\end{tabular}

All data are presented as means \pm SD. $* \mathrm{p}<0.05$ vs control

Feeding experimental rats the HFHC diet for 12 weeks led to hyperglycemia. This can be evidenced by an increased fasting plasma glucose level (Table 2). As a result of glucose tolerance test, $30 \mathrm{~min}$ after the oral administration of glucose to rats in the experimental group, the blood glucose level exceeded that in the control by $23.3 \%(\mathrm{p}<0.05)$, after 60 and $120 \mathrm{~min}$ - by $30.9 \%(\mathrm{p}<0.05)$ and $28.6 \%(\mathrm{p}<0.05)$ respectively (Fig. 1). The area under the curve glucose concentration-time $\left(\mathrm{AUC}_{0-120}\right)$ in the experimental group of animals was $818.2 \pm 61.4 \mathrm{mmol} / 1 \times 120 \mathrm{~min}$ and exceeded the control group value $(622.1 \pm 36.8 \mathrm{mmol} / 1 \times 120 \mathrm{~min}, \mathrm{p}<0.05)$.

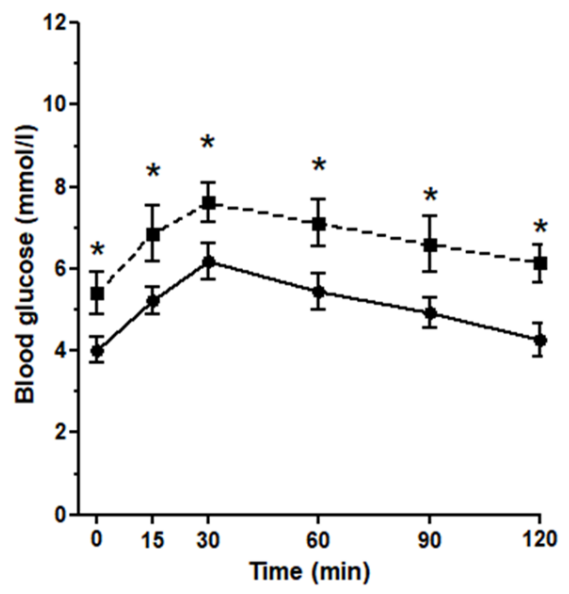

Fig. 1. Effects of high-fat and high-carbohydrate (HFHC) diet on a blood glucose in rats. All data are presented as means \pm SD. $* \mathrm{p}<$ 0.05 vs control

Dyslipidemia as the characteristic of MetS demonstrates both quantitative and qualitative changes in the blood lipoprotein composition. The most important signs of dyslipidemia are an increased level of TAG, a high level of LDL, and also a decreased level of HDL [2].

Rats in the experimental group showed an increase in the amount of TAG in blood plasma by 2,5 times compared with the control group. The total cholesterol $(\mathrm{Ch})$ level in the blood of animals fed a HFHC diet increased by 1,5 times (Table 2). At the same time, the level of atherogenic LDL increased in rats of the experimental group, while the level of HDL did not change (Table 2). A positive correlation was found between the concentration of TAG and an increase in the adipose tissue/body weight ratio $(r=0.689, p<0.05)$. A relationship was found between the concentration of glucose in the blood and the adipose tissue/body weight ratio $(\mathrm{r}=0.823, \mathrm{p}<0.05)$.

TABLE II BIOCHEMICAL PARAMETERS OF RATS

\begin{tabular}{|l|c|c|}
\hline \multirow{2}{*}{\multicolumn{1}{|c|}{ Parameter }} & \multicolumn{2}{|c|}{ Group } \\
\cline { 2 - 3 } & $\begin{array}{c}\text { Control } \\
(\mathrm{n}=11)\end{array}$ & $\begin{array}{c}\text { HFHC } \\
(\mathrm{n}=12)\end{array}$ \\
\hline $\begin{array}{l}\text { Fasting glucose, } \\
\mathrm{mmol} / \mathrm{l}\end{array}$ & $4.0 \pm 0.3$ & $5.4 \pm 0.5^{*}$ \\
\hline Insulin, $\mathrm{pmol} / \mathrm{l}$ & $12 \pm 2.1$ & $17.6 \pm 2.8^{*}$ \\
\hline Total $\mathrm{Ch}, \mathrm{mmol} / \mathrm{l}$ & $1.7 \pm 0.2$ & $2.5 \pm 0.3^{*}$ \\
\hline HDL, $\mathrm{mmol} / \mathrm{l}$ & $1.0 \pm 0.2$ & $0.8 \pm 0.1$ \\
\hline LDL, $\mathrm{mmol} / 1$ & $0.7 \pm 0.3$ & $1.6 \pm 0.4^{*}$ \\
\hline TAG, $\mathrm{mmol} / \mathrm{l}$ & $0.9 \pm 0.4$ & $2.3 \pm 0.8^{*}$ \\
\hline
\end{tabular}

All data are presented as means $\pm \mathrm{SD} . * \mathrm{p}<0.05$ vs control

Although MetS is mainly a metabolic disorder, this condition can be regarded also as a state of oxidative stress. MetS is characterized not only by high blood glucose that contributes to the generation of free radicals, but also by elevated free fatty acids [5]. Oxidative stress and chronic inflammation in MetS cause a significant impairment of hemorheology, where erythrocytes play a special role.

The level of GSH antioxidant in the erythrocyte lysate obtained from animals with MetS was reduced in comparison with the control group, while the level of MDA as an oxidative stress marker was statistically significantly increased in the group of rats with MetS (Fig. 2).

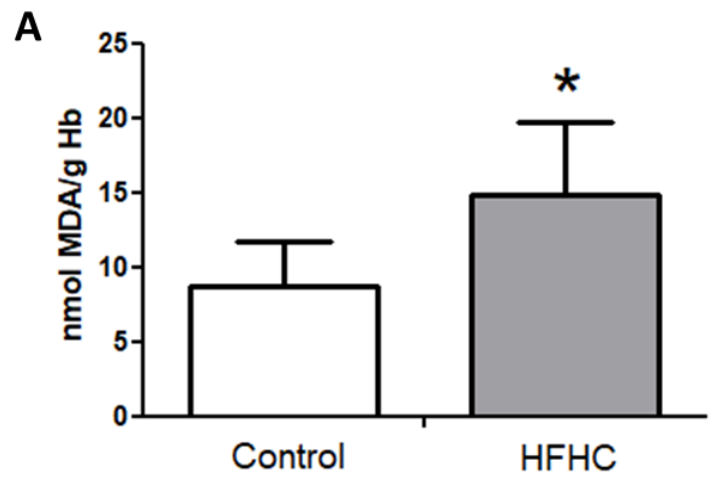


B

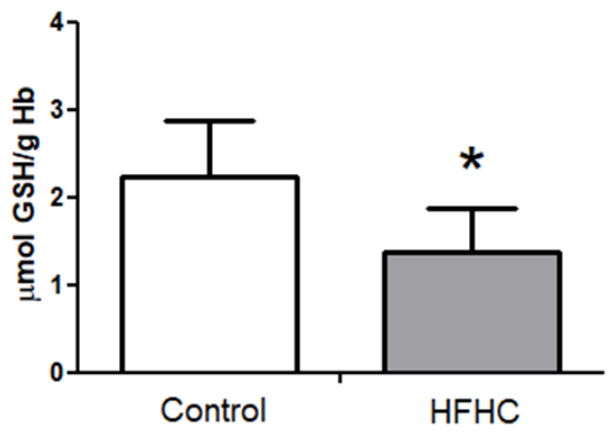

Fig. 2. Oxidative stress biomarkers: (A) Malondialdehyde (MDA) levels in erythrocytes; (B) Glutathione (GSH) levels in erythrocytes. All data are presented as means \pm SD. $* p<0.05$ vs control

Metabolic disorders and structural disorganization of the red blood cell membrane are reflected in the change of their ion transport function.

As shown in Figure 3, in rats fed a HFHC diet the amplitude of erythrocyte hyperpolarization stimulated by the $\mathrm{Ca}^{2+}$ ionophore A23187 decreased in comparison with the control group. The membrane potential of erythrocytes in the experimental group was $-31.1 \pm 5.5 \mathrm{mV}$ and $-39.4 \pm 3.4 \mathrm{mV}$ ( $\mathrm{p}<$ 0.05 ) in the control group, respectively. In contrast, the amplitude of hyperpolarization obtained by adding an electron donor system ascorbate-PMS to the erythrocyte suspension was increased in rats in the experimental group. The membrane potential of erythrocytes in the experimental group was $-48.1 \pm 4.2 \mathrm{mV}$ and $-41.6 \pm 5.2 \mathrm{mV}(\mathrm{p}<0.05)$ in the control group, respectively.

\section{A}

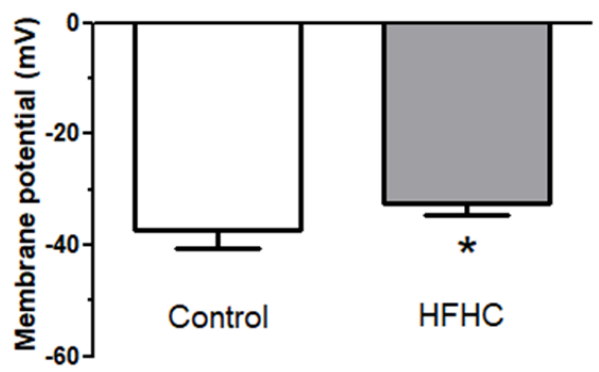

B

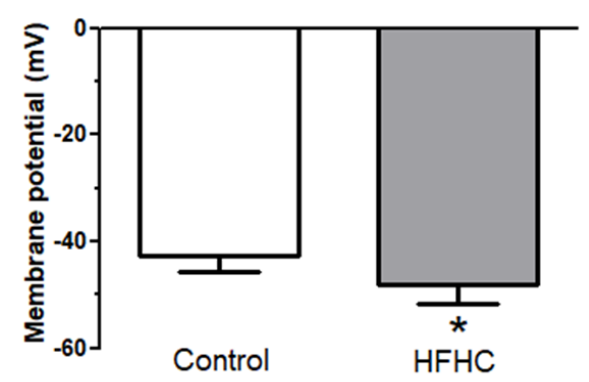

Fig. 3. Changes in erythrocyte hyperpolarization upon activation of $\mathrm{K}_{\mathrm{Ca}}$ channels by A23187 (A) or by the ascorbate-PMS (B). All data are presented as means $\pm \mathrm{SD}$. $* \mathrm{p}<0.05$ vs control

\section{Discussion}

The experimental animal models are used to study the mechanisms of development and progression of metabolic and hemorheological disorders in MetS [6], [13], [20]. They are aimed to reproduce the specific signs of MetS, such as overweight, obesity, insulin resistance, impaired glucose tolerance, dyslipidemia, and arterial hypertension [1], [2]. One of the possible way to induce MetS in animals is the HFHC diet.

In our study, it was found that feeding rats a diet containing animal fat, fructose and cholesterol for 12 weeks led to obesity, increased BP, hyperglycemia, decreased glucose tolerance, dyslipidemia with severe triglyceridemia. Dyslipidemia in MetS is usually a combination of changes in lipid fractions, including mainly high levels of TAG [14], [21]. Although overt hypercholesterolemia is not typical for MetS. In our study, a significant increase in blood plasma TAG was observed in the experimental group, which may be due to the lipogenic effect of fructose. High consumption of fructose leads to an accumulation of glycolysis intermediates which can be converted to glycerol-3-phosphate used in triglyceride synthesis. Chronic intake of fructose increases de novo lipogenesis by activating several key transcription factors such as Sterol Response Element Binding Protein 1c (SREBP1c) and Carbohydrate-Responsive Element-Binding Protein (ChREBP). As a consequence, their key target enzymes regulating lipid synthesis such as Fatty Acid Synthase (FASN) and Acetyl-CoA Carboxylase (ACC) also increase as shown, for example, in a western diet where fructose is provided as a $30 \%$-fructose containing beverage for eight weeks [22]. The results are consistent with the literature data on diet-induced MetS models and indicate that the chosen diet effectively reproduces the clinical signs of MetS [5], [13].

It is known that obesity, as one of the important components of MetS, is accompanied by a chronic inflammatory process and causes systemic oxidative stress, and the occurrence of oxidative stress in adipose tissue is considered as the main cause of adipokine dysregulation and the development of MetS [23], [24]. Oxidative stress causes ratio distortion between prooxidant and antioxidant factors in favor of prooxidants. Oxidative stress and inflammation play an important role in vascular diseases and circulatory disorders [25], [26]. In this study, it was found that rats with MetS had increased oxidative stress as compared to the control, which also leads to depletion of erythrocyte antioxidant defense mechanisms due to the overproduction of reactive oxygen species [27]. Erythrocytes can be considered an ideal cell to protect other body tissues from free radical damage even at the expense of their own structure and function. Carrying out their role of free radical scavengers, erythrocytes become damaged by oxidation, which consumes endogenous-reducing substances thereby decreasing the level of GSH antioxidant. These observations are consistent with the studies that have highlighted oxidative stress as a pathophysiological component of MetS [24].

Experimental and clinical studies carried out in recent years 
suggest that the pathogenetic mechanisms of MetS are inextricably linked with the functioning of the blood system. Changes in the physical and chemical properties and structural disorganization of the erythrocyte plasma membrane in metabolic disorders also lead to dysregulation of its cation transport function, where $\mathrm{K}_{\mathrm{Ca}}$ channels play an important role [9], [10]. Stimulation of erythrocyte $\mathrm{K}_{\mathrm{Ca}}$ channels was carried out using the $\mathrm{Ca}^{2+}$ ionophore $\mathrm{A} 23187$ or an electron donor system ascorbate-PMS, which led either to an increase in the intracellular concentration of $\mathrm{Ca}^{2+}$ ions or to an increase in the channel's affinity for $\mathrm{Ca}^{2+}$. The activation of $\mathrm{K}_{\mathrm{Ca}}$ channels occurs in response to increase of concentrations of $\mathrm{Ca}^{2+}$ ions, which leads to leakage of potassium ions from cells and, as a result, to hyperpolarization of the erythrocyte membrane [8], [10]. In response to the stimulation of the $\mathrm{K}_{\mathrm{Ca}}$ channels of the erythrocyte membrane A23187 or ascorbate-PMS, multidirectional changes in the amplitude of the membrane potential were observed. The observed effect can be explained by the increased concentration of calcium ions in the erythrocytes of rats with MetS.

Change in the amplitude of membrane potential caused by the calcium ionophore and the ascorbate-PMS system may be due to different mechanisms of the $\mathrm{K}_{\mathrm{Ca}}$ channel activation [19]. In addition, an increase in the amplitude of ascorbate-PMSinduced hyperpolarization of the erythrocyte membrane, observed in the experimental group, indicates an increased conductivity of the $\mathrm{K}_{\mathrm{Ca}}$ channels of the erythrocyte membrane. However, the ascorbate-PMS system, inducing the formation of redox agents, exerts its influence on the $\mathrm{Ca}^{2+}$-dependent potassium permeability of the erythrocyte membrane indirectly through SH-groups [28]. At the same time, the structural rearrangement of the lipid composition of the membrane caused by increased cholesterol incorporation and externalization of phosphatidylserine, which leads to an increase in the microviscosity of the lipid bilayer [21], [25] and a decrease in cell deformability in the vascular bed, has a significant effect on the activity of $\mathrm{K}_{\mathrm{Ca}}$ channels. Changes in the structural organization of the erythrocyte membrane in a number of pathologies will disrupt the regulation mechanisms of $\mathrm{Ca}^{2+}$-dependent potassium permeability of the red blood cell membrane.

\section{CONCLUSION}

In the present study, we created a model of MetS using animal fat (lard) and carbohydrates (fructose) in the food of animals. Unlike most of the models described in the literature, we used relatively small amounts of these additives, aiming to mimic the "cafeteria diet" typical of unhealthy nutrition habits of a modern man. Nevertheless, this diet was associated with significantly higher caloric intake. It was found that the use of the proposed HFHC diet in rats reproduces most of the typical MetS signs: obesity, increased blood pressure, hyperglycemia, decreased glucose tolerance, insulin resistance, dyslipidemia with triglyceridemia.

In the current study, we showed that the level of glutathione
(GSH) decreased in the erythrocytes of rats suffering from MetS, but the level of marker of prooxidant status malondialdehyde (MDA) increased. It was shown that the amplitude of the membrane potential of erythrocytes of rats with MetS changed depending on the acting agent: when stimulated with calcium ionophore A23187 it decreased, when the redox system ascorbat - phenazine methosulfate was used, it increased as compared to the control group.

The negative effect of chronic inflammation and oxidative stress on the cardiovascular system in MetS could be due to the altered hemorheology. The revealed changes in the $\mathrm{Ca}^{2+}$ dependent potassium permeability of the red blood cell membrane in animals kept on a HFHC diet are associated with oxidative stress and physical and chemical rearrangements of the erythrocyte membrane in case of MetS. The results obtained are valuable from the standpoint of studying the causes of the development and progression of cardiovascular diseases associated with MetS.

\section{REFERENCES}

[1] M.G. Saklayen, "The Global Epidemic of the Metabolic Syndrome," Curr. Hypertens. Rep. vol. 20, no. 2, pp. 12, 2018.

[2] M.K. Lee, K. Han, M.K. Kim, E.S. Koh, E.S. Kim, G.E. Nam et al., "Changes in metabolic syndrome and its components and the risk of type 2 diabetes: a nationwide cohort study," Sci. Rep., vol. 10, no. 1, pp. 2313, 2020.

[3] M.J. Fowler, "Microvascular and Macrovascular Complications of Diabetes," Clinical Diabetes, vol. 2008, pp. 77-82, 2008.

[4] A.F. Catoi, A.E. Parvu, A.D. Andreicut, A. Mironiuc, A. Craciun, C. Catoi et al., "Metabolically Healthy versus Unhealthy Morbidly Obese: Chronic Inflammation, NitroOxidative Stress, and Insulin Resistance," Nutrients, vol. 10, no. 9, pp. 1199, 2018.

[5] F.V. Francisqueti, A.F. Nascimento, I.O. Minatel, M.C. Dias, R. Luvizotto, C. Berchieri-Ronchi et al., "Metabolic syndrome and inflammation in adipose tissue occur at different times in animals submitted to a high-sugar/fat diet," J. Nutr. Sci., vol. 6, pp. e41. 2017.

[6] G.F. Monteomo, A. Kamagate, A.P. Yapo, "Effects of metabolic syndrome on blood cells to Wistar rats," J. Diabetes Metab. Disord. Control, vol. 5, no. 6, pp. 222225,2018

[7] P. Gyawali, R.S. Richards, "Association of altered hemorheology with oxidative stress and inflammation in metabolic syndrome," Redox Rep., vol. 20, no. 3, pp. 139-144, 2015.

[8] F. Lang, E. Lang, M. Föller, "Physiology and pathophysiology of eryptosis," Transfus. Med. Hemother., vol. 39, no. 5, pp. 308-314, 2012.

[9] L. Kaestner, X. Wang, L. Hertz, I. Bernhardt "VoltageActivated Ion Channels in Non-excitable Cells - A Viewpoint Regarding Their Physiological Justification," Front. Physiol., vol. 9, pp. 450. 2018. 
[10] A. Bogdanova, A. Makhro, J. Wang, P. Lipp, L. Kaestner, "Calcium in Red Blood Cells - A Perilous Balance," Int. J. Mol. Sci., vol. 14, pp. 9848-9872, 2013.

[11]E. Matteucci, O. Giampietro, "Electron Pathways through Erythrocyte Plasma Membrane in Human Physiology and Pathology: Potential Redox Biomarker?" Biomark Insights, vol. 2, pp. 321-329, 2007.

[12]A.E. Kwitek, "Rat models of metabolic syndrome," Methods Mol. Biol., vol. 2018, pp. 269-285, 2019.

[13] C. Marques, M. Meireles, S. Norberto, J. Leite, J. Freitas, D. Pestana et al., "High-fat diet-induced obesity Rat model: a comparison between Wistar and SpragueDawley Rat," Adipocyte, vol. 5, no. 1, pp. 11-21. 2015.

[14] S. Moreno-Fernández, M. Garcés-Rimón, G. Vera, J. Astier, J.F. Landrier, M. Miguel, "High Fat/High Glucose Diet Induces Metabolic Syndrome in an Experimental Rat Model," Nutrients, vol. 10, no 10, pp. 1502, 2018.

[15] J.G. Birulina, V.V., Ivanov E.E., Buyko, V.V. Bykov, L.V. Smagliy, A.V. Nosarev et al., "High-fat, highcarbohydrate diet-induced experimental model of metabolic syndrome in rats," Bulletin of Siberian Medicine, vol. 19, no. 4, pp. 14-20, 2020.

[16] I. Rahman, A. Kode, S.K. Biswas, "Assay for quantitative determination of glutathione and glutathione disulfide levels using enzymatic recycling method," Nat. Protoc., vol. 1, no. 6, pp. 3159-3165, 2006.

[17] S.K. Jain, S.N. Levine, J. Duett, B. Hollier, "Elevated lipid peroxidation levels in red blood cells of streptozotocin-treated diabetic rats," Metabolism, vol. 39, no. 9, pp. 971-975, 1990.

[18] H.M. Staines, W. Chang, J.C. Ellory, T. Tiffert, K. Kirk, V.L. Lew, "Passive $\mathrm{Ca}(2+)$ transport and $\mathrm{Ca}(2+)$ dependent $\mathrm{K}(+)$ transport in Plasmodium falciparuminfected red cells," J. Membr. Biol., vol. 172, no. 1, pp. 13-24, 1999.

[19]I.V. Petrova, Yu.G. Birulina, S.N. Belyaeva, O.A. Trubacheva, A.V. Sidekhmenova, L.V. Smagliy et al. "The Effects of Gasomediators on the $\mathrm{Ca} 2+-$ Dependent Potassium Permeability of the Erythrocyte Membrane," Biophysics, vol. 65, pp. 614-618, 2020.

[20] R.K. Suman, I.R. Mohanty, M.K. Borde, U. Maheshwari, Y.A. Deshmukh, "Development of an Experimental Model of Diabetes Co-Existing with Metabolic Syndrome in Rats," Adv. Pharmacol. Sci., vol. 2016, pp. 9463476. 2016.

[21] J.S. Perona, "Membrane lipid alterations in the metabolic syndrome and the role of dietary oils," Biochimica et Biophysica Acta (BBA) - Biomembranes, vol. 1859, is. 9, part B, pp. 1690-1703, 2017.

[22] M.A. Herman, V.T Samuel, "The sweet path to metabolic demise: Fructose and lipid synthesis," Trends Endocrinol. Metab. vol. 27, pp. 719-730. 2016.

[23] S. Spahis, J.M. Borys, E. Levy, "Metabolic Syndrome as a Multifaceted Risk Factor for Oxidative Stress," Antioxid. Redox Signal., vol. 26, no. 9, pp. 445-461, 2017.

[24] M. Sankhla, T.K. Sharma, K. Mathur, J.S. Rathor, V. Butolia, A.K. Gadhok et al., "Relationship of oxidative stress with obesity and its role in obesity induced metabolic syndrome," Clinical Laboratory, vol. 58, pp. 385-392. 2012.

[25]E. Kowalczyk, J. Kowalski, J. Błaszczyk, Ł. Gwoździński, J. Ciećwierz, M. Sienkiewicz, "Estimation of cell membrane properties and erythrocyte red-ox balance in patients with metabolic syndrome," Mol. Biol. Rep., vol. 39, no. 12, pp. 11113-11118, 2012.

[26] R. Vona, L. Gambardella, C. Cittadini, E. Straface, D. Pietraforte, "Biomarkers of Oxidative Stress in Metabolic Syndrome and Associated Diseases," Oxid. Med. Cell Longev., vol. 2019, pp. 8267234, 2019.

[27]P. Gyawali, R.S. Richards, P.T. Bwititi, E.U. Nwose, "Association of abnormal erythrocyte morphology with oxidative stress and inflammation in metabolic syndrome," Blood Cells Mol, Dis., vol. 54, no. 4, pp. 360-363, 2015.

[28] Y.G. Birulina, I.V. Petrova, Y.A. Rozenbaum, E.A. Shefer, L.V. Smagliy, A.V. Nosarev et al., "H2SMediated Changes in Erythrocyte Volume: Role of Gardos Channels, $\mathrm{Na}+, \mathrm{K}+, 2 \mathrm{Cl}-$ Cotransport and Anion Exchanger," Bull. Exp. Biol. Med., no 7, pp. 508-511, 2019.

\section{Author Contributions}

Yuliya Birulina and Vladimir Ivanov conceived and designed the research.

Irina Petrova interpreted the data and drafted the manuscript.

Evgeniy Buyko analyzed the data and prepared the figures.

Rashel Shaibekova and Anna Grigoreva performed the experiments.

Yuliya Birulina, Igor Kovalev, Alexey Nosarev and Svetlana Gusakova and edited and revised the manuscript. All authors approved the final version of the manuscript.

\section{Sources of funding}

The study was funded by The Council for Grants of the President of the Russian Federation (CS-143.2020.4).

\section{Creative Commons Attribution License 4.0 (Attribution 4.0 International, CC BY 4.0)}

This article is published under the terms of the Creative Commons Attribution License 4.0 https://creativecommons.org/licenses/by/4.0/deed.en_US 